\title{
Fifth Ventricle
}

National Cancer Institute

\section{Source}

National Cancer Institute. Fifth Ventricle. NCI Thesaurus. Code C32602.

A normal variant CSF filled cavity in the brain situated between the leaves of the septum pellucidum. Also called cavum septi pellucidum. 